\title{
Correction to: Kinesiophobia modulates lumbar movements in people with chronic low back pain: a kinematic analysis of lumbar bending and returning movement
}

\author{
Michihiro Osumi $^{1} \cdot$ Masahiko Sumitani $^{2} \cdot$ Yuko Otake $^{2} \cdot$ Tomohiko Nishigami $^{3} \cdot$ Akira Mibu $^{3} \cdot$ Yuki Nishi $^{1}$. \\ Ryota Imai ${ }^{1} \cdot$ Gosuke Sato $^{1} \cdot$ Yusuke Nagakura $^{1} \cdot$ Shu Morioka ${ }^{1}$
}

Published online: 13 June 2019

(c) Springer-Verlag GmbH Germany, part of Springer Nature 2019

\section{Correction to: European Spine Journal https://doi.org/10.1007/s00586-019-06010-4}

In the figure 2, "CLBP Low fear" which located right end of Time of Phase 1 is wrong. The correct statement is "CLBP High fear". The complete correct figure 2 is given below.
Publisher's Note Springer Nature remains neutral with regard to jurisdictional claims in published maps and institutional affiliations.
Fig. 2 Comparison of phase duration among groups.

\#Significant difference between CLBP high-fear and HC group $(p<0.017) .{ }^{\S}$ Significant difference between CLBP high-fear and CLBP low-fear groups $(p<0.017)$
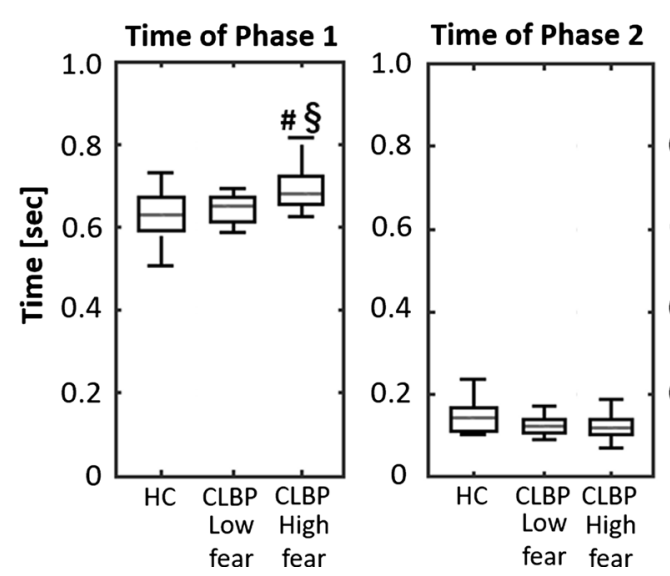

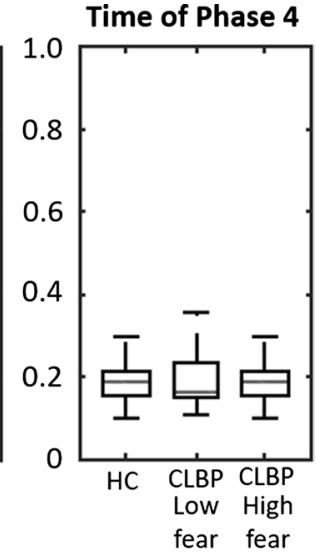

The original article can be found online at https://doi.org/10.1007/ s00586-019-06010-4.

Michihiro Osumi

m.ohsumi@kio.ac.jp

1 Graduate School of Health Science, Kio University, 4-2-2

Umaminaka, Koryo-cho, Kitakatsuragi-gun, Nara 635-0832, Japan

2 Department of Pain and Palliative Medicine, The University of Tokyo Hospital, Tokyo, Japan

3 Department of Nursing and Physical Therapy, Konan Woman's University, Kobe, Hyogo, Japan 